\title{
Literary Theory and Psychological Reading Models
}

The Affective Fallacy is a confusion between the poem and its results (what it is and what it does).... It begins by trying to derive the standard of criticism from the psychological effects of the poem and ends in impressionism and relativism.

-Monroe C. Beardsley and W. K. Wimsatt, "The Affective Fallacy"

However disciplined by taste and skill, the experience of literature is, like literature itself, unable to speak.

- Northrop Frye, Anatomy of Criticism

American literary theory has seen an explosion of interest in readers and reading. There is talk of implied readers, informed readers, fictive readers, ideal readers, mock readers, superreaders, literents, narratees, interpretive communities, and assorted reading audiences. The term "reader-response criticism" has been used to describe a multiplicity of approaches that focus on the reading process: affective, phenomenological, subjective, transactive, transactional, structural, deconstructive, rhetorical, psychological, speech act, and other criticisms have been indiscriminately lumped together under the label "reader response." In these first two chapters I will bring some order into this metacritical chaos by comparing the most prominent models of reading and the critical theories based on those models. To do this, I will investigate the work of the five reader-response critics who have been most influential in the United States: Stanley Fish, Norman Holland, David Bleich, Wolfgang Iser, and Jonathan Culler. Out of this investigation 


\section{Interpretive Conventions}

will come an agenda for developing a reader-oriented approach to American fiction study.

\section{Reader-Response Criticism?}

All reader-response critics focus on readers during the process of reading. Some examine individual readers through psychological observations and participation; others discuss reading communities through philosophical spcculation and literary intuition. Rejecting the Affective Fallacy of American New Criticism, all describe the relation of text to reader. Indeed, all share the phenomenological assumption that it is impossible to separatc perceiver from perceived, subject from object. Thus they reject the text's autonomy, its absolute separateness, in favor of its dependence on the reader's creation or participation. Perception is viewed as interpretive; reading is not the discovery of meaning but the creation of it. Reader-response criticism replaces examinations of a text in-and-of-itself with discussions of the reading process, the "interaction" of reader and text.

Stanley Fish's early essay, "Literature in the Reader: Affective Stylistics" (1970) presented onc influential version of this reader-response criticism. Fish viewed a sentence in the text not as "an object, a thing-in-itself, but an event, something that happens to, and with the participation of, the reader." His claims were aggressively descriptive: "In my method of analysis, the temporal flow is monitorcd and structured by everything the reader brings with him, by his competences; and it is by taking these into account as they interact with the temporal left-to-right reception of the verbal string that I am able to chart and project the developing responsc." 1 And the developing response was that of the "informed reader," a reader with the ability to understand the text and have the experience the author intended. ${ }^{2}$ In this

1. "Literature in the Reader: Affective Stylistics," New Literary History, 2 (1970); rpt. in Fish, Is There a Text in This Class?: The Authority of Interpretive Communities (Cambridge: Harvard University Press, 198o), pp. 25, 46-47.

2. See Fish, "Literature in the Reader," pp. 48-49; and two other articles by Fish: "What Is Stylistics and Why Are They Saying Such Terrible Things About It?" in Approaches to Poetics, ed. Seymour Chatman (New York: Columbia University Press, 1973), and "Interpreting the Varionum," Critical Inquiry, 2 (1976), both rpt. in Is There a Text in This Class?: see esp. pp. 379-80 and 159-61. 


\section{Literary Theory and Psychological Reading Models}

"affective stylistics," Fish talked as if a text manipulated the reader - the text forced the reader to perform certain cognitive acts - and Fish, as practical critic, described that manipulative process. As a critical theorist Fish attacked formalist approaches, especially American New Criticism, for ignoring "what is objectively true about the activity of reading." He claimed that his own approach was in contrast "truly objective" because it recognized the "fluidity ... of the meaning experience" and directed our attention "to where the action is-the active and activating consciousness of the reader." 3

In a major reversal, Fish rejects these claims in "Interpreting the Variorum" (1976), where he argues that all texts are in fact constituted by readers' interpretive strategies and that the process he formerly claimed to describe is actually a creation of his critical theory: "What my principles direct me to 'see' are readers performing acts; the points at which I find (or to be more precise, declare) those acts to have been performed become (by a sleight of hand) demarcations in the text; those demarcations are then available for the designation 'formal features,' and as formal features they can be (illegitimately) assigned the responsibility for producing the interpretation which in fact produced them." ${ }^{4}$ This radical revision of Fish's theory has two consequences: a change in the relation of reader to text and a change in the relation of criticism to reading. Fish now claims that in reading the interpreter constitutes the text and that in reader criticism the interpreter's description constitutes the nature of the reading process according to his interpretive strategies.

Fish has moved from a phenomenological emphasis (which describes the interdependence of reader and text) to a structuralist or even post-structuralist position (which studies the underlying systems that determine the production of textual mean-

3. Fish, "Literature in the Reader," p. 44.

4. Fish, "Interpreting the Variorum," p. 163. The introduction and headnotes to the essays reprinted in Fish's Is There a Text in This Class? provide the best discussion of the course and consequences of Fish's move from his earlier to his later critical theory. For a critique of this move, see Steven Mailloux, "Stanley Fish's 'Interpreting the Variorum': Advance or Retreat?" Critical Inquiry, 3 (1976), 183-9o; and for Fish's convincing response to this critique, see his "Interpreting 'Interpreting the Variorum,'" same issue, rpt. in Is There a Text in This Class?, pp. $174-80$. 


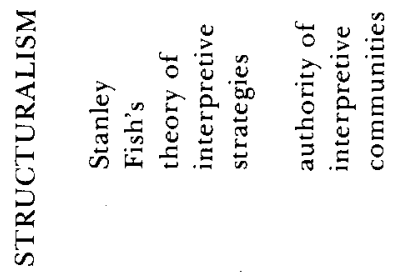

通車命

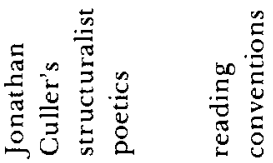

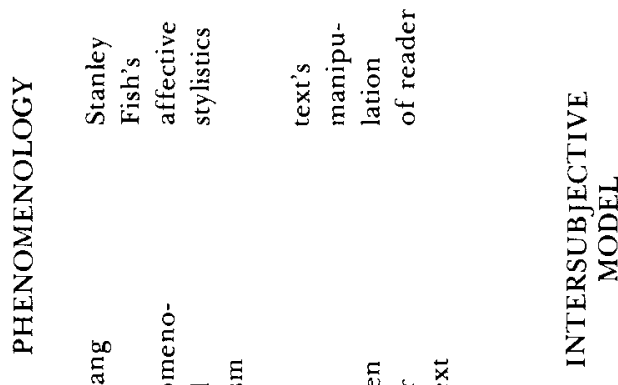

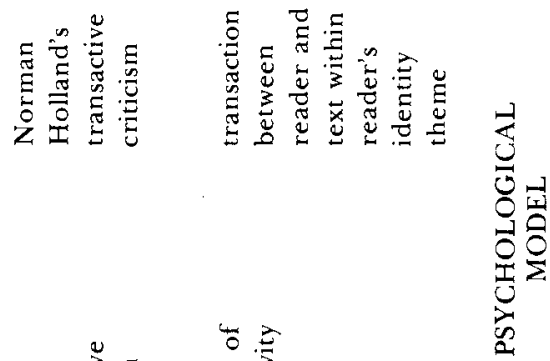

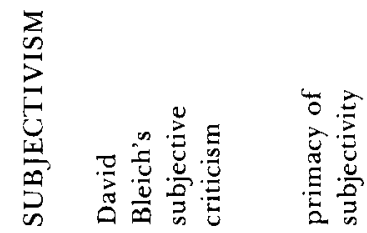




\section{Literary Theory and Psychological Reading Models}

ing and in which the individual reader and the constraining text lose their independent status). In his metacriticism, Fish has given up making descriptive claims for his earlier critical approach and abandoned its absolute priority over formalist criticism. He now views affective stylistics as only one of many possible interpretive strategies; it does not describe how all readers read but instead suggests one way they could read. Though Fish now holds it to be an act of persuasion rather than objective description, he continues to use his earlier approach when he does practical criticism. He therefore occupies two places on the schema of reader-response criticism shown in the chart.

This schema locates each critic on a continuum of readeroriented approaches. A detailed examination of these approaches will reveal not only the interrelations among the critics placed here but also the problems within each of their readerresponse theories. All five critics construct a theory consisting (in more or less detail) of an account of interpretation, a model for critical exchange, and a model of reading. These critics' theories of interpretation try to account for meaning-production in both reading and criticism. Their models of critical discussion specify the nature of critical procedures (observation, description, explication, and explanation) and the ways interpretations are exchanged in critical dialogue. These hermeneutic theories and critical models are based on models of reading, accounts of how readers actually interact with the text during the temporal reading process. Norman Holland's work provides a useful starting point for the following discussions of reader-response criticism because his writings carefully examine all three of these components making up a critical theory. ${ }^{5}$

5. I do not intend these three levels of the critical enterprise to be exhaustive. For example, I have deliberately excluded a component for literary evaluation, since most reader-response critics find hierarchies of literary values irrelevant to their descriptive projects. (But see Steven Mailloux, "Evaluation and Reader Response Criticism: Values Implicit in Affective Stylistics," Style, 1o [1976], 329-43.) My purpose here is not to provide a detailed discussion of these three components of critical theory but to use this tripartite division as a loose framework for the analyses that follow. Cf. Leroy Searle, "Tradition and Intelligibility: A Model for Critical Theory," New Literary History, 7 (1976), 402 and 415 , n. 29 . 


\section{Interpretive Conventions}

\section{Transactive Criticism}

Holland's transactive criticism "takes as its subject-matter, not the text in supposed isolation, as the New Criticism claimed it did, nor the self in rhapsody, as the old impressionistic criticism did, but the transaction between a reader and a text." ${ }^{6}$ The notion of an "identity theme" is central to Holland's approach: "we can be precise about individuality by conceiving of the individual as living out variations on an identity theme much as a musician might play out an infinity of variations on a single melody." A person brings this "unchanging inner core of continuity" to all transactions between Self and Other, including reading. ${ }^{7}$

Holland's model of reading proceeds from his more general theory of the relation between personality and perception. Perception is a "constructive act," not merely reflecting but forming reality: "the individual apprehends the resources of reality (including language, his own body, space, time, etc.) as he relates to them in such a way that they replicate his identity." 8 That is, perception is also interpretation, and "interpretation is a function of identity, specifically identity conceived as variations upon an identity theme." Holland particularizes this view of perception in his central thesis about reading: identity re-creates itself. "All of us, as we read, use the literary work to symbolize and finally to replicate ourselves. We work out through the text our own characteristic patterns of desire and adaptation."

Within this principle of identity re-creation, Holland isolates four specific modalities, which he conveniently organizes under the acronym DEFT-defenses, expectations, fantasies, and transformations. "One can think of these four separate principles as emphases on one aspect or another of a single transaction: shaping an experience to fit one's identity and in doing so, (D) avoiding anxiety, (F) gratifying unconscious wishes, (E) absorbing the event as part of a sequence of events, and $(T)$ shap-

6. Norman N. Holland, "Transactive Criticism: Re-Creation Through Identity," Criticism, 18 (1976), 334 .

7. Holland, "Unity Identity Text Self," $P M L A, 9^{\circ}$ (1975), 814; "Transactive Criticism," p. 338 .

8. Holland, "The New Paradigm: Subjective or Transactive?" New Literary History, 7 (1976), 343 .

9. Holland, "Unity," p. 816 . 


\section{Literary Theory and Psychological Reading Models}

ing it with that sequence into a meaningful totality." ${ }^{10}$ The concept of a "meaningful totality" or unity is pivotal for Holland's reading model (and is equally important in his general theory of interpretation). ${ }^{11}$ According to Holland, the reader makes sense of the text by creating a meaningful unity out of its elements. Unity is not in the text but in the mind of a reader. "By means of such adaptive structures as he has been able to match in the story, he will transform the fantasy content, which he has created from the materials of the story his defenses admitted, into some literary point or theme or interpretation." ${ }^{12}$ For Holland, meaning is the result of this interpretive synthesis, the transformation of fantasy into a unity which the reader finds coherent and satisfying. As with all interpretation, "the unity we find in literary texts is impregnated with the identity that finds that unity." Each reader creates a unity for a text out of his own identity theme, and thus "each will have different ways of making the text into an experience with a coherence and significance that satisfies." 13 Therefore, Holland's model of reading accounts exceptionally well for varied responses.

On the other hand, Holland's present theory has trouble with the phenomenon of similar responses. Similarity was easily explained by his earlier model. In The Dynamics of Literary Response (1968), he spoke as if "fantasies and their transformations were embodied in the literary work, as though the work itself acted like a mind"; different readers could take in ("introject") the

10. Holland, "Transactive Criticism," p. 342. For other accounts of DEFT, see Holland, Poems in Persons: An Introduction to the Psychoanalysis of Literature (New York: Norton, 1973), pp. $76-78 ; 5$ Readers Reading (New Haven: Yale University Press, 1975), pp. 113-28; "Unity," pp. 816-18; and "The New Paradigm," p. $33^{8}$.

11. As Holland writes, "Identity is the unity I find in a self if I look at it as though it were a text" ("Unity," p. 815). He further explains that "interpretation is a function of identity, identity being defined operationally as what is found in a person by looking for a unity in him, in other words, by interpretation. We seem to be caught in a circular argument, but it is not the argument which is circular-it is the human condition in which we cannot extricate an 'objective' reality from our 'subjective' perception of it" ("Transactive Criticism," p. 340).

12. Holland, 5 Readers Reading, pp. 121-22; for a detailed description of this transformational process, see Holland, The Dynamics of Literary Response (New York: Oxford University Press, 1968), chs. i-vi.

13. Holland, "Unity," p. 816, emphasis added. 


\section{Interpretive Conventions}

same text and "participate" in whatever psychological process was embodied there. Accounting for recurrent responses has become much more difficult in Holland's revised model, in which "processes like the transformation of fantasy materials through defenses and adaptations take place in people, not in texts."14 No longer embodying psychological processes, autonomous texts no longer serve as a guarantee of recurrence in Holland's present model of reading. Instead, similar identity themes must somehow account for similar response. ${ }^{15}$ This psychological explanation contrasts with Fish's "sociological" ones. In Fish's earlier theory, all informed readers had the same basic reading experience because they shared linguistic and literary competence; in his present theory, communal reading strategies account for similar interpretive responses. The comparison between Fish's and Holland's reading models becomes more complex when we examine the precise status of the text in their revised theories. ${ }^{16}$

Holland and Fish both claim that perception is a constructive act: we interpret as we perceive, or rather, perception is an interpretation. For Fish, interpretive strategies constitute the text; not even as words-on-the-page does the text have any autonomy. As soon as we read, we interpret; and thus our interpretive strategies create the text that we later discuss in critical exchange. Holland seems to hold a similar view: "A literary text, after all, in an objective sense consists only of a certain config-

14. Holland, 5 Readers Reading, p. 19, and see Holland, "A Letter to Leonard," Hartford Studies in Literature, 5 (1973), 9-3o.

15. Cf. Holland, "Unity," p. $81_{5}$ : "the same identity theme may describe several different people."

16. The difference between Fish's and Holland's present models of reading is not that one accounts for similarities and the other for differences. Both models claim to account for both kinds of response: shared interpretive strategies and similar identity themes explain recurrence, and different interpretive strategies and dissimilar identity themes account for variability. Rather, the relevant distinction here is the ability to account for unique, idiosyncratic responses. Holland's model allows the possibility of a unique personality and thus a unique interpretive response. Fish's present model denies the possibility of a unique interpretation because idiosyncratic interpretive strategies are impossible; strategies for making sense are always shared strategies, according to Fish--see Is There a Text in This Class?, pp. 14, 335, 338. For how Fish's earlier model of reading accounted for differences and similarities in response, see ibid., pp. 4-6, 15 . 


\section{Literary Theory and Psychological Reading Models}

uration of specks of carbon black on dried wood pulp. When these marks become words, when those words become images or metaphors or characters or events, they do so because the reader plays the part of a prince to the sleeping beauty." ${ }^{17}$ However, Holland runs into the same problem as Fish: if interpretation constitutes the text, what is the interpretation of? Fish throws up his hands: "I cannot answer that question, but neither, I would claim, can anyone else, although formalists try to answer it by pointing to patterns and claiming that they are available independently of (prior to) interpretation." ${ }^{18}$ Holland tries to solve the paradox but in so doing necessarily equivocates. In one place he writes, "A reader reads something, certainly, but if one cannot separate his 'subjective' response from its 'objective' basis, there seems no way to find out what that 'something' is in any impersonal sense." ${ }^{9}$ Throughout Poems in Persons (1973), however, Holland constantly refers to "raw materials" in the text, which are presumed to be separate from the reader, not created by his interpretation during the reading process. The reader "reaches into the poem and takes materials from it with which to achieve an experience within the characteristic pattern of ego choices he uses to minimize anxiety and cope with reality." ${ }^{20}$ Holland often gives these "raw materials" a status inconsistent with his emphasis on the reader's total domination of the text's meaning. He mentions (but does not explain) "constraints" in the work ${ }^{21}$ and speaks of doing "violence" to the text. ${ }^{22}$ For example, he writes that "different builders can assemble the same stones into a building in many different ways, with more and less violence to the raw materials, just as different readers

17. Holland, 5 Readers Reading, p. 12.

18. Fish, "Interpreting the Variorum," p. $16_{5}$.

19. Holland, 5 Readers Reading, p. 40.

20. Holland, Poems in Persons, pp. $15^{-16}$, emphasis added. See also pp. 77 , $96,99,117,145$, and 147 .

21. Ibid., pp. 96, 148 . Cf. Holland, 5 Readers Reading, p. 286 : “To be sure, the promptuary [the structured language of the words-on-the-page] includes constraints on how one can put its contents together, but these constraints do not coerce anyone." The point to notice here is not that Holland claims constraints can be ignored (all critics admit this) but that he assumes constraints are in the text and need only be recognized (not created) by readers.

22. Holland, Poems in Persons, pp. 118,146 . Cf. Holland, 5 Readers Reading, pp. $219-20$. 
can construct different experiences of a poem, with more and less contortion of the words and the plain sense." 23 These references to raw materials, plain sense, and constraints all suggest a preexistent text independent of a reader's interpretation and experience.

Holland's discussions of response in 5 Readers Reading (1975) also assume some aspects of the text prior to interpretation; he often talks about elements of a story that are combined according to the reader's identity theme. ${ }^{24} \mathrm{He}$ does not focus on how these elements (language, dialogue, character, plot) are constituted (are they in the text as raw materials or are they also constructed in the transaction?). Holland's discussion of interpretation occurs at a higher level of reader activity. That is, the story (as a combination of preexistent elements) is re-created by the reader's identity through the modalities of DEFT, and interpretation ("the making sense") is a unity that the story takes on for the reader. Put another way, for Holland, meaning is the output of a psychological process; the input to that process is the story. Like Holland, Fish believes that meanings are "not extracted but made," but he claims further that the text is constituted (in all its aspects) by the interpretive process and is not prior to it. ${ }^{25}$

Concerning the nature of critical discussion, the form of Fish's and Holland's arguments is the same; both use the interpretive

23. Holland, Poems in Persons, pp. $116-17$.

24. See, for example, Holland, 5 Readers Reading, pp, 116-19. But perhaps a phrase such as "elements in the story" or "materials of the story" is merely what Holland calls a "useful fiction" (p. 19), for he writes in another place that the reader "will try to make the language, events, or people he creates from the text function in multiple directions to work out the compromise among the demands of inner and outer reality that is his own style" (p. 126, emphasis added). Still, he never qualifies such statements as: "The difference [in experiences] comes from the differences in character. The sameness comes from the sameness in the resources used to create the experience" (pp. 247-48).

25. Fish, "Interpreting the Variorum," p. 172. In more recent formulations of his model, Holland continues to deny that "the text limits response in any significant way" but still writes that "the literent [reader] builds a personal response by a personal use of the several elements of the text, a response that the text may or may not reinforce. In a transactive model, I am engaged in a feedback loop (or, to be less technical, a dialogue) with the text. I bring schemata to bear on the text, and the text either does or does not reward them." (These statements are from Holland's exchange with Iser in "Interview: Wolfgang Iser," ed. Rudolf E. Kuenzli, Diacritics, 10 , No. $2\left[19^{80}\right], 5^{8,60 .)}$ 


\section{Literary Theory and Psychological Reading Models}

operations they describe for readers as explanations for the interpretive acts performed by critics. For Fish, critics interpret in their criticism in basically the same way they interpret as they read. Similarly, Holland views critics "as simply another group of readers operating under special stringencies"; in reading and criticism the process is the same: re-creation through identity. ${ }^{26}$ For Holland, the critic's interpretation is merely an extension of the reader's interpretive synthesis. And since "all interpretations express the identity themes of the people making the interpretations," the interpretations by critics ("professional readers") are also manifestations of their identity themes. ${ }^{27}$

Since Fish and Holland agree that we do criticism in the same way that we read (that is, we use the same interpretive strategies in reading and criticism), their explanations of recurrent responses carry over to their discussions of critical consensus. Fish presents a sociological argument, Holland a psychological one. Fish moves from the community to its members, Holland from the individual to the group. Critics agree when they belong to the same interpretive community, says Fish; and interpretive communities "are made up of those who share interpretive strategies not for reading (in the conventional sense) but for writing texts, for constituting their properties and assigning their intentions." ${ }^{28}$ Holland argues that critics agree when they can assimilate the others' identity re-creations into their own. He implies that this agreement can take place either because two critics have similar identity themes or because two critics with widely divergent identity themes are still able to utilize each other's interpretations in their own re-creations. People "distinguish different readings of a text or personality 'objectively' by how much and how directly they seem to us to bring the details of a text or a self into convergence around a centering theme. We also compare them as to whether they 'feel right' or 'make sense.' That is, do we feel we could use them to organize and make coherent our own experience of that text or person?" 29

26. Holland, "A Letter to Leonard," p. 21.

27. Holland, "Unity," p. 816; 5 Readers Reading, p. 246. Cf. Holland, Poems in Persons, p. 129.

28. Fish, "Interpreting the Variorum," p. 171.

29. Holland, "Unity," p. 816. Also see Holland, Poems in Persons, pp. 125-26. 


\section{Interpretive Conventions}

However, Holland again goes against the grain of his theory by using "raw materials" in the text to help explain critical agreement. For example, in discussing a similar theme arrived at by three different readers, he argues that "this consensus does not come about simply because the poem 'caused' it, but because the three readers all took some of the same elements from the poem to make up their individual syntheses." And again: "We see consensus because different readers are using the same material." 30

In terms of their overall critical projects, both Fish and Holland try to present compact conceptual frameworks. Their theories of interpretation provide explanatory centers (interpretive communities or identity themes) which account for the acts of reading, criticism, and critical exchange, though Holland's model of reading has difficulty in consistently explaining similar responses and critical agreement.

\section{Subjective Criticism}

On several occasions David Bleich and Norman Holland have exchanged views on each other's work. ${ }^{31}$ Their conversation in print at times proves especially illuminating not only for what it shows about the contrast between their two approaches, but also for how it illustrates their shared differences from other reader-oriented critics. In Readings and Feelings (1975), Bleich's model of reading consists of perception, affect, and association. Like Holland, Bleich holds that "the perception of the poem is a subjective reconstruction rather than a simple recording of facts," and he sometimes discusses a reader's "style of perception," the forms of "individuated perception created by the particular biases of the reader." A reader's report of perception tells "what he sees in the poem or what he thinks the poet says," while reports of affective response describe "the actual affect [fear,

3o. Holland, Poems in Persons, pp. 115-16.

31. See, for example, Holland, "A Letter to Leonard," pp. $21-28$, "The New Paradigm," pp. 335-45, and 5 Readers Reading, p. 407, n. 52; David Bleich, "Pedagogical Directions in Subjective Criticism," College English, 37 (1976), 462-63, and "The Subjective Paradigm in Science, Psychology, and Criticism," New Literary History, 2 (1976), 332; and Norman N. Holland and David Bleich, "Comment and Response," College English, $3^{8}$ (1976), 298-301. 


\section{Literary Theory and Psychological Reading Models}

satisfaction, indignation, etc.] he felt while reading the poem."32 Associative response embodies those aspects of the reader's previous experience that are stimulated by the affect derived from his reading experience.

Like most reader-response approaches, Bleich's subjective criticism places meaning in readers, not in texts. Bleich explicitly rejects the notion of an objective text completely independent of the reader, but he does not wrestle with the problematic relation of interpretation to text during the reading process. Instead, he refers primarily to critical interpretation, an activity subsequent to the reading experience: "For the reader, the interpretation is the response to his reading experience." ${ }^{33}$

Bleich's most recent book, Subjective Criticism (1978), presents the most detailed elaboration of his views on interpretation and reading, and here Bleich is more consistent than Holland in developing the absolute priority of individual selves as creators of texts. ${ }^{34}$ However, this same rigorous consistency provides Bleich's theory with its own problems. For though Subjective Criticism is challenging in its pedagogical proposals and wideranging in its use of interdisciplinary resources, it is ultimately incomplete as a hermeneutic project. The book outlines a framework for literary engagement that begins with the individual reader as the center of critical concern. Bleich's model progresses from subjective response, to resymbolization, to negotiation resulting in validated knowledge. We need to examine each step in this model before considering the problems in Bleich's theory of interpretation.

On the level of reading: "Subjective response" refers to an individual reader's "first perceptual initiative toward a symbolic object" (p. 96). When there are no prior utilitarian motives constraining these initiatives, response will be an act of "evaluative symbolization"- a combination of perception and affect-which serves as the basis for all further discussions of the text (p. 98).

32. David Bleich, Readings and Feelings: An Introduction to Subjective Criticism (Urbana, Ill.: NCTE, 1975), pp. 27-33.

33. Bleich, "The Subjective Character of Critical Interpretation," College English, 36 (1975), 754 .

34. Bleich, Subjective Criticism (Baltimore: Johns Hopkins University Press, 1978). All page citations in the text of this section refer to this book. 


\section{Interpretive Conventions}

In fact, for Bleich the text as symbolic object does not exist prior to or independent of subjective initiative. It is only on the basis of such individual subjective creations that interpretation can proceed.

On the level of criticism: The second stage in Bleich's model, resymbolization, occurs when the first acts of perception and identification-the subjective response or symbolization-produce in the reader "a need, desire, or demand for explanation" (p. 39). Resymbolization "is the conceptualization of symbolized objects and processes in terms of subjective motives" (p. 88). In most cases, resymbolization is motivated and motivational explanation: it is motivated by the initial subjective response which requires an explanation, and it is motivational in that the explanation provided is in the form of psychological motives. This individual resymbolization "is commonly known as interpretation" (p. 67).

In the third and most problematic stage of Bleich's model, the level of critical exchange, individual interpretations are negotiated within communities and new knowledge is produced. Negotiations in Bleich's classes, for example, begin with an individual student's "response statement," which Bleich defines as "a symbolic presentation of self, a contribution to a pedagogical community, and an articulation of that part of our reading experience we think we can negotiate into knowledge" (p. 167). Response statements resymbolize individual reading experiences in terms of perceptions, affects, and associations (as described in Readings and Feelings), and these resymbolizations are then negotiated into knowledge about language and literature.

In discussing negotiation, Bleich writes that "the synthesizing of communal knowledge cannot begin without the substrate of individual subjective knowledge" (p. $\left.15^{1}\right)$. This statement points to a problem area within Bleich's hermeneutic theory: the dynamics of moving from the individual to the communal. Given the primacy of the individual self as creator of texts, how can Bleich's model account for agreement in negotiation? More specifically, if, as Bleich argues, texts are functions of individual subjective initiatives, resymbolized on an individual basis, how can different subjectivities participate in a negotiating process? What is negotiated, and how? Since texts are individually consti- 
tuted, readers might be able to share their resymbolizations in a kind of show-and-tell ritual, ${ }^{35}$ but "negotiation" seems a rather misleading name for such a process because the term suggests some kind of interpretive trade-off. Furthermore, following Bleich's logic, response statements must have the same ontological status as literary works: as texts, both are constituted by subjective initiative. In negotiation, then, there could be a different version of each negotiator's response statement created by each of his or her fellow negotiators, just as all the response statements represent (constitute) various versions of the literary text (or reading experience). Each reader creates a different text, which when shared is constituted differently by different perceivers. If no text (either literary or critical) is prior to individual initiative, no negotiating process is comprehensible, let alone possible in practice.

The strongest attempt that Bleich makes to resolve this hidden impasse is his explanatory use of the concept of "motive." Within his theory, motives function as explanations of subjective response in resymbolization and of resymbolization itself. In both cases, motives serve as why's and not how's: "a motive is a subjectively regulated cause and is the name for causes originating in human initiative" (p. 44). Bleich also attempts to use motives to explain the dynamics of negotiating resymbolizations, and, as I have noted, here is where he runs into problems: how to move from individually motivated responses to negotiated consensus. He attempts to bridge the gap by positing a category of shared motives, such as a desire to reach consensus, a need for perceptual validation, or a goal of self-enhancement. However, this move explains why negotiation occurs but not how it works. Unlike Thomas Kuhn's "paradigms" or Fish's "interpretive strategies" (to which Bleich refers), "motives" cannot provide specific constraints for insuring the possibility of shared interpretations.

Bleich has, in fact, presented himself with an apparently impossible task: to account for interpretive agreement after having established the absolute primacy of the individual as interpreter. This theoretical impasse is buried by his attempt to associate his

35. See, for example, Bleich, Subjective Criticism, p. 98. 


\section{Interpretive Conventions}

individualistic model of reading with interpretive theories that have agreement built into them from the start. Bleich points to what he sees as theoretical analogues to negotiated consensus, first in Kuhn's concept of paradigm ${ }^{36}$ and then in Fish's notion of interpretive community. Unfortunately, Bleich appears to misunderstand the social foundation of the work by these theorists he takes to be his allies.

Bleich at first seems well aware of the social basis of Kuhn's notion of paradigm, which Bleich defines as "a shared mental structure, a set of beliefs about the nature of reality subscribed to by a group of thinkers large enough to exercise leadership for those similarly wishing to observe and understand human experience" (p. 1o). Furthermore, he takes what I would call a "maximally constitutive" view of Kuhn's central concept: a dominant paradigm does not simply guide the perception and investigation of nature, it constitutes nature itself. This interpretation of Kuhn's theory makes it look very much like Bleich's. Just as for Bleich there is no text prior to subjective response, for a maximally constitutive paradigm theory, there is no reality independent of a paradigm. "The paradigmatic perception of reality at any moment in history is the reality at that time. The implication of this thought is that for all practical purposes, reality is invented and not observed or discovered by human beings" (p. 11). Bleich then proceeds to distort the social nature of Kuhn's paradigm theory in the following way.

When Bleich speaks of "the socially subjective character of knowledge" (p. 25), he means "consensually validated perception" (p. 11). For Bleich, "knowledge in general comes through synthesized interpretations" (p. 33), that is, negotiated consensus. The "common world of sense," then, is "determined by extended negotiation among perceivers" (p. 20). Bleich believes Kuhn's position is essentially in agreement with his own on these matters. I do not think this is the case at all. Bleich talks about consensus reached after perception, but Kuhn emphasizes shared examplars prior to and constituting perception. Bleich's consensus is achieved after negotiation; Kuhn's shared paradigms are what

36. Thomas S. Kuhn, The Structure of Scientific Revolutions, 2d ed. (Chicago: University of Chicago Press, 1970). 
make negotiations possible. In fact, Kuhn's sociological theory directly contradicts Bleich's psychological model of individuated perception. For Kuhn, initial perceptions are communal, not individual, with paradigms being shared by scientists (in the same community) from the start. ${ }^{37}$ If Bleich wants help explaining how individual subjective responses and resymbolizations become validated knowledge through negotiation, he will not find it in Kuhn's theory of paradigms.

Nor will Fish's account of interpretive communities provide the needed theoretical support. Bleich construes Fish's theory in a way Fish would not accept. Specifically, Bleich fails to realize that the communities he refers to are radically different from the interpretive communities Fish describes. ${ }^{38}$ In his later theory, Fish agrees with Bleich that there is no text prior to interpretation. For Fish, however, interpretation is a communal affair from the outset, constrained by shared interpretive strategies. Texts are constituted by interpretive communities, which consist of interpreters who share ways of reading (and therefore constructing) texts. For Bleich, communities are groups where negotiations of resymbolizations take place; a community exists so that new knowledge can be synthesized in discussions. The interpretive communities Fish describes form the basis for such discussions; they provide the conditions necessary for the interpretive and persuasive acts that Bleich's negotiators perform.

A single community (in Bleich's sense) can consist of representatives from several interpretive communities (in Fish's sense). Fish's communities can include members not present (that is, interpreters who share strategies but are not members of

37. At least during periods of normal science-see Kuhn, pp. 23-51. In conversations that I have found very helpful, Bleich has suggested to me that his use of Kuhn focuses not on periods of normal science but on periods of paradigm revolutions, more exactly on the movement from paradigm uncertainty to new paradigm acceptance. Even here, however, I think Bleich and Kuhn are talking about two radically different processes. For Kuhn, a new paradigm becomes established not through Bleich's two-way negotiation but through one-way persuasion in which holders of the new paradigm (sometimes) convert holders of the old and no new-paradigm holders seem to be converted back to the old paradigm-see Kuhn, pp. 150-52.

38. Bleich discusses Fish's theory in Subjective Criticism, pp. 122-26. 


\section{Interpretive Conventions}

Bleich's discussion group). Thus, interpretive communities cannot be viewed simply as physical groupings of individuals with similar concerns (p. 125); rather they are constitutive of the discussions taking place within those groupings. For Bleich, MLA meetings, classrooms, and journal forums are the communities in which individuals come to consensus (or fail to achieve it) ${ }^{39}$ For Fish, such physical spaces have little to do with the set of members composing interpretive communities; membership in an interpretive community is not determined by proximity or similar concerns, but by shared ways of interpreting. Consensus can then be seen as the agreement articulated in critical discussion; shared interpretive strategies assure that agreement, providing the foundation for its recognition.

As with Kuhn's concept of paradigms, Bleich misses an essential point about Fish's notion of interpretive communities. Bleich cannot use either of these sociological theories to support his attempt to move from individual subjectivities to group consensus, because agreement is built into these theories from the start as it can never be in Bleich's psychological account. Negotiation as ongoing accomplishment and consensus as achieved goal remain unexplained in Bleich's interpretive theory.

I have discussed these two examples of misunderstanding at such length because I believe they are symptomatic of Bleich's central theoretical problem. His discussions of Kuhn and Fish unintentionally disguise a theoretical impasse which, if it continues unacknowledged and unresolved, will undermine the most important goal of Subjective Criticism. That goal is a bold one: to reinscribe the organized discussion of literature within a discourse that aggressively advocates the freedom of the individual self in a pedagogical community. Bleich's approach to teaching places the individual student and his subjective response at the center of literary study. "Subjective criticism assumes that each person's most urgent motivations are to understand himself," Bleich writes in his final paragraph. These pedagogical premises challenge teachers to reevaluate their notions of authority, to reexamine their attitudes toward their stu-

39. See Bleich, "Negotiated Knowledge of Language and Literature," Studies in the Literary Imagination, 12, No. 1 (1979), 73-92. 


\section{Literary Theory and Psychological Reading Models}

dents, and to redefine their rationales for teaching literature. Such challenges raise basic questions that deserve serious consideration. Unfortunately, such consideration may be withheld because a problematic theory of interpretation supports Bleich's pedagogical program. The problems in his account of negotiation need to be resolved before discussions of his challenging proposals for teaching can proceed. ${ }^{40}$

Bleich shares with Holland this pedagogical focus, which distinguishes both of their theories from those of Iser, Fish, and Culler. ${ }^{41}$ However, Bleich and Holland have found many places to disagree over their respective theoretical projects. For example, Bleich views the subjective/objective distinction as absolute and therefore criticizes Holland's transactive paradigm, which denies that absoluteness. Holland claims that "objective reality' and 'pure experience' are themselves only useful fictions, vanishing points we approach but never reach. The problem, then, is not to sort out subjective from objective but to see how the two

4o. Since the publication of Subjective Criticism, Bleich appears to have recognized some of the problems with the concept of negotiation but not the particular issues I have raised in this section; see Bleich, "Negotiated Knowledge," p. 75, n. 1. In conversation he has pointed out to me that he considers Subjective Criticism as a first attempt to establish an area of study and understand it, and he feels it already looks forward to further examinations of how the individual relates to the social, especially in terms of language, e.g., see Subjective Criticism, pp. 265 and 296.

41. See, for example, Holland, 5 Readers Reading, pp. 108-18, and Holland and Murray Schwartz, "The Delphi Seminar," College English, 36 (1975), 7898oo. Long before either Bleich or Holland began working on the problem, Louise Rosenblatt argued for the pedagogical relevance of the reader's individual experience of literature. See Louise M. Rosenblatt, Literature as Exploration (New York: Appleton-Century, 1938); the third edition (1976) is presently distributed by the Modern Lañguage Association. In her most recent book, Rosenblatt is critical of "aggressively subjective approaches" to reading (presumably Bleich's and Holland's) and argues that her "transactional view, while insisting on the importance of the reader's contribution, does not discount the text and accepts a concern for validity of interpretation"-Louise M. Rosenblatt, The Reader, the Text, the Poem: The Transactional Theory of the Literary Work (Carbondale: Southern Illinois University Press, 1978), p. 151. Though it puts greater emphasis on the individuality of reading experiences, Rosenblatt's transactional theory more closely resembles Iser's phenomenology than Holland's and Bleich's psychological perspectives. Perhaps this is because Rosenblatt's work derives from that of William James, to whom Edmund Husserl expressed indebtedness (see Rosenblatt, The Reader, p. $111 \mathrm{n}$.), and because Husserl's phenomenology is the ultimate source (by way of Ingarden) for Iser's theory. For Bleich's comments on Rosenblatt's work, see Subjective Criticism, pp. 108-10. 


\section{Interpretive Conventions}

combine when we have experiences." ${ }^{42}$ Bleich rejects this view and criticizes Holland's "assumptions and formulations" which "continue to try to appease the demands of objectivity." 43 For Bleich, Holland is simply not subjective enough.

Nonetheless, despite their differences, Holland and Bleich can be grouped together in that they define their critical paradigm (subjective or transactive) from a psychological perspective (not a sociological one). They emphasize the individual over the group; reading is a function of personality, not shared strategies. Furthermore, Bleich and Holland both study the reported responses of readers in developing their theories. As Holland remarks, "it is the close analysis of what readers actually say about what they read that differentiates" readerresponse critics like himself and Bleich from those like Iser and Fish (and he could have included Culler as well). ${ }^{44}$

The kind of critical project that Holland and Bleich advocate runs counter to the dominant activities of American literary study. Practical criticism, for example, currently depends on intersubjective theories of literature which make possible critical consensus and validity in interpretation; while textual scholarship requires a communication model of reading which assumes the availability of authorial intention. As I have shown in this chapter, both Holland and Bleich have difficulties providing this intersubjective basis for reading and criticism: Holland lapses into assertions about a preexistent text that contradict the thrust of his theory, and Bleich, who is more consistent in assuming individual readers as creators of texts, cannot move convincingly from individual response to group consensus. Furthermore, both Holland and Bleich explicitly reject any communication model for reading. Holland argues that "interpretation is not decoding. Each reader constructs meaning as part of his own artistic experience.... He does not recover some preexisting intention latent in the work." 45 And Bleich's "logic of interpre-

42. Holland, Poems in Persons, p. 2.

43. Bleich, "The Subjective Paradigm," p. 332; and see Bleich, Subjective Criticism, pp. $111-22$

44. Holland, "Unity," p. 882, n. 8 .

45. Holland, Poems in Persons, p. 117 ; cf. p. 99: "The poet does not speak to 
tation excludes consideration of whether and how the author is communicating anything to us." 46 Without an intersubjective foundation or a communication model, Holland and Bleich's psychological approach to reader-response criticism will have a very difficult time influencing the institutional study of literature.

the reader directly so much as give the reader materials from which to achieve the poem in his own style." See similar claims in Holland, 5 Readers Reading, pp. 2 1 8-19. Holland has presented some alternatives to traditional practical criticism in his self-conscious "transactions" of literary texts in "Hamlet-My Greatest Creation," Journal of the American Academy of Psychoanalysis, 3 (1975), 419-27; "Transacting My 'Good-Morrow' or, Bring Back the Vanished Critic," Studies in the Literary Imagination, 12, No. 1 (1979), 61-72; and "Re-Covering "The Purloined Letter': Reading as a Personal Transaction," in The Reader in the Text, ed. Susan R. Suleiman and Inge Crosman (Princeton: Princeton University Press, 1980), pp. $35^{0-70}$; and with others, Holland presents a collective transaction of a poem in "Poem Opening: An Invitation to Transactive Criticism," College English, 40 (1978), 2-16.

46. Bleich, Subjective Criticism, pp. 95-96; and see pp. 89, 93; also cf. pp. 259, $262-63$ on "The Conception and Documentation of the Author." 